Check for updates

Cite this: Mater. Adv., 2021, 2, 6075

Received 10th August 2021, Accepted 13th August 2021

DOI: 10.1039/d1ma00709b

rsc.li/materials-advances

\section{Regulation of the bi-color fluorescence changes of AIE supramolecular self-assembly gels by interaction with $\mathrm{Al}^{3+}$ and energy transfer}

\author{
Xinxian Ma, D $\ddagger^{*^{a}}$ Jinlong Yue, $\ddagger^{a}$ Bo Qiao, ${ }^{a}$ Lili Zhou, ${ }^{a}$ Yang Gao, ${ }^{a}$ Yipei Wang, ${ }^{a}$ \\ Yingshan Lai, ${ }^{a}$ Yutao Geng, ${ }^{a}$ Enke Feng (D ${ }^{a}$ and Minghua Liu (D) *b
}

\begin{abstract}
Supramolecular fluorescent materials have attracted considerable attention in recent years since they endow specific and unique properties to materials. Nevertheless, the utilization of photoresponsive characteristics to modulate their fluorescence emission behaviors and functions remain rarely explored. Here a facile fabrication strategy for producing dual-emissive materials based on supramolecular gels is proposed. A bi-acylhydrazone supramolecular gelator BD was designed and synthesized by a Schiff base reaction. Interestingly, the gelator $\mathrm{BD}$ could self-assemble into the stable supramolecular gel BDG with a strong aggregation-induced emission (AIE) in DMF $-\mathrm{H}_{2} \mathrm{O}$ binary solutions via $\pi-\pi$ stacking interactions. On the one hand, the BDG could selectively identify $\mathrm{Al}^{3+}$ in the gel state. Upon addition of $\mathrm{Al}^{3+}, \mathrm{AlE}^{\mathrm{BDG}}$ showed an obvious blue-shift ( $85 \mathrm{~nm}$, from yellow-green to sky-blue). On the other hand, artificial light-harvesting systems were successfully fabricated in a gel environment based on the supramolecular strategy. In these systems, efficient energy transfer occurs between the BD assembly and the loaded acceptors. For instance, the transition from yellow-green to red light could be accomplished in the BDG/SR 101 system. Based on these, the manipulation of bi-color fluorescence emission was realized by interaction with $\mathrm{Al}^{3+}$ and energy transfer.
\end{abstract}

\section{Introduction}

The phenomenon and concept of the aggregation-induced emission (AIE) of organic compounds, proposed by Tang and co-workers in $2001,{ }^{1}$ have been attracting considerable research interest and it has shown extensive application prospects in many fields, including chemical sensing, ${ }^{2}$ fluorescent sensors, ${ }^{3}$ and bioimaging. ${ }^{4}$ In the AIE process, AIEgens exhibit strong fluorescence emission in the aggregated state, ${ }^{5,6}$ which is different from the aggregation-caused quenching (ACQ) effect. Supramolecular materials, ${ }^{7}$ where the component molecules are combined together through noncovalent bonds, have been attracting great interest. In these systems, AIE has provoked much wholesale academic interest for innovative practical applications.

\footnotetext{
${ }^{a}$ College of Chemistry and Chemical Engineering, Ningxia Normal University, Guyuan 756000, People's Republic of China. E-mail: maxinxian@163.com; Tel: +86-954 2079637

${ }^{b}$ CAS Key Laboratory of Colloid, Interface and Chemical Thermodynamics, Institute of Chemistry, Chinese Academy of Sciences, Beijing, P. R. China.

E-mail: liumh@iccas.ac.cn; Tel: +86-10-82615803

$\dagger$ Electronic supplementary information (ESI) available. See DOI: 10.1039/d1ma00709b \# These authors contributed equally to this work. They should thus be considered co-first authors.
}

Supramolecular gels can be constructed by single noncovalent interactions or by the combination of multiple noncovalent interactions. ${ }^{8}$ By comparison, the dynamic and reversible properties of multiple noncovalent interactions endow supramolecular gels with an excellent response to various external stimuli, such as heat, light, $\mathrm{pH}$, and metal cations. ${ }^{8}$ Moreover, the gel is a soft substance between a liquid state and a solid state, and a large amount of solvent molecules are fixed/wrapped by gelators, in which the solvent can contribute also. These characteristics provide a broad scope for the fabrication of smart materials and devices.

The recognition and sensing of metal ions have become the focus of considerable attention in biological, chemical, material, and environmental fields. ${ }^{9,10}$ Aluminum is the third most abundant of all the elements (after oxygen and silicon) in the earth's crust, ${ }^{11,12}$ accounting for $8.3 \%$ of the earth's total mineral components. However, a high aluminum intake can damage the central nervous system and is involved in Alzheimer's disease, Parkinson's disease, bone softening, chronic renal failure, and smoking-related diseases. ${ }^{13}$ Accordingly, the development of convenient and efficient testing methods for $\mathrm{Al}^{3+}$ is of great significance for environmental protection and human health. In this way, developing a fluorescent chemosensor for the selective recognition and monitoring of $\mathrm{Al}^{3+}$ in environmental systems or in living cells ${ }^{14}$ is essential. 
Photosynthesis plays a vital role in the survival foundation of organisms, in which the large number of closely packed antenna pigments (ca. 200) around the reaction center is applied in the energy transfer and accumulation of sunlight. $^{15-18}$ Several scaffolds have shown extraordinary results in mimicking the natural light-harvesting process by achieving efficient energy transfer from donors to acceptors through a Förster resonance energy transfer (FRET) process,${ }^{19,20}$ such as protein assemblies, ${ }^{21}$ dendrimers, ${ }^{22}$ metal complex polymers, and porphyrin assemblies. These artificial light-harvesting systems/materials are of significant importance for practical applications, which are still less emphasized in the gel state to date. ${ }^{23}$

Fluorophores with aggregation-induced emission properties are good candidates for the construction of fluorescent supramolecular systems. However, supramolecular gels with tunable emission have been rarely reported, although some progress has recently been made on the construction of discrete fluorescent supramolecular assemblies. ${ }^{24}$ Traditionally, more than one kind of fluorophores should be incorporated to construct this kind of gel, thus resulting in complexity in the designed systems. Besides this method, the emission behavior could also be tuned by the introduction of interactions with ions, hostguest interactions, or other forms of interaction, ${ }^{9,10,23}$ resulting in a change in the emission wavelength. Herein, we report a biacylhydrazone compound, which was found to exhibit competitive guest stimuli responsiveness in the gel state and AIE properties. The stable organogel (BDG) showed a selective and sensitive stimuli-response for $\mathrm{Al}^{3+}$ but the $\mathrm{BD}$ in solution could not detect $\mathrm{Al}^{3+}$ in our fluorescence analysis experiments. Moreover, efficient light-harvesting systems (LHSs) were successfully fabricated using the organogel BDG as an energy donor, and a series of dyes, such as sulforhodamine 101, acridine red, rhodamine $\mathrm{B}$, and rhodamine $6 \mathrm{G}$, were utilized as energy acceptors, respectively. Additionally, the fluorescence color and emission spectrum of $\mathrm{BD}$ could be effectively tuned by metal ion coordination or by fabricating light-harvesting systems. As far as we know, this is the first report that connects self-assembly, AIE activity, light-harvesting, and ion recognition through a multifunctional bi-acylhydrazone derivative (Scheme 1).

\section{Experimental}

\subsection{Materials and general methods}

For the materials, 2-(2-hexyl-1H-benzimidazole-1-yl)acetohydrazide, terephthalaldehyde, organic solvent and metal salt were purchased from commercially available sources and were used without further purification. Deionized water was used for all the experiments. The measurements of steady-state luminescence were performed with a Shimadzu RF-5301PC spectrometer and spectrofluorophotometer (F-4500, Japan). Ultraviolet-visible (UV-vis) spectra were recorded on a Shimadzu UV-1750 spectrometer. The infrared spectra were recorded on a Thermo Scientific Nicolet iS5 FT-IR spectrophotometer. Fluorescence micrographs (FOM) of the samples were obtained with an Olympus IX 71 system. The ${ }^{1} \mathrm{H}$ and ${ }^{13} \mathrm{C}$ NMR spectra were recorded on a Bruker $400 \mathrm{MHz}$ spectrometer. The internal standard was TMS and the solvent was dimethylsulfoxide (DMSO- $d_{6}$ ). Time-resolved photoluminescence decay measurements were carried out using a time-correlated single-photon counting (TCSPC) spectrometer (Edinburgh, FLS 980). Mass spectra were obtained on a Bruker solanX 70 FT-MS mass spectrometer equipped with an ESI interface and ion-trap analyzer. The morphologies of the as-synthesized samples were characterized with an SM-74190UEC SEM system using an accelerating voltage of $10 \mathrm{kV}$. The quantum yield was measured on an FLS980 fluorescence spectrometer. X-ray diffraction patterns (XRD) were determined with a X'Pert PRO diffractometer using $\mathrm{Cu}-\mathrm{K}_{\alpha}$ radiation over the $2 \theta$ range of $5-90^{\circ}$.

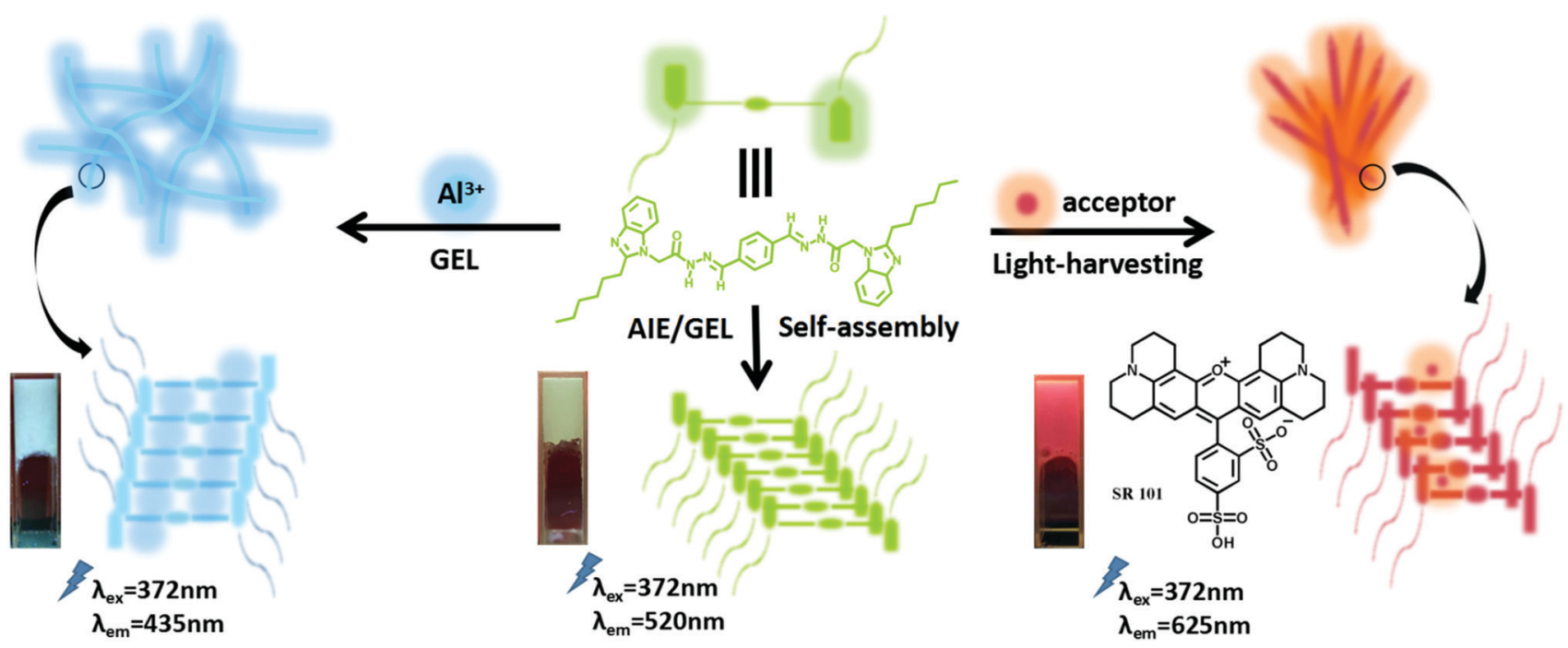

Scheme 1 Schematic representation for the bi-color fluorescence changes of a bi-acylhydrazone compound. 


\subsection{Synthesis of the compounds}

As shown in Scheme 2, 2-(2-hexyl-1H-benzimidazole-1-yl)acetohydrazide $(6.855 \mathrm{~g}, 25 \mathrm{mmol})$ and terephthalaldehyde $(1.341 \mathrm{~g}, 10 \mathrm{mmol})$ with a molar ratio of $2.5: 1$ were dissolved in DMF $(100 \mathrm{~mL})$. The mixture was stirred under reflux at $80{ }^{\circ} \mathrm{C}$ for $8 \mathrm{~h}$ with acetic acid added (2-3 drops). After the reaction was finished and the solution cooled to room temperature, the precipitate was collected by filtration, washed three times with hot absolute ethanol, and then dried in a vacuum; giving a faint yellow powder compound BD (5.030 g, yield: $61 \%) .{ }^{1} \mathrm{H}$ NMR (400 MHz, DMSO- $d_{6}$, Fig. S1, ESI $\dagger$ ) (ppm): 11.88 (d, 2H, N-H), 8.31-8.11 (d, 2H, $\mathrm{N}=\mathrm{CH}), 7.94-7.15(\mathrm{~m}, 12 \mathrm{H}, \mathrm{ArH}), 5.49-5.03$ (d, 1H). ESI-MS: $m / z 647.4\left(\left[\mathrm{C}_{38} \mathrm{H}_{46} \mathrm{~N}_{8} \mathrm{O}_{2}\right]+\mathrm{H}\right)^{+}$(Fig. S3, ESI $\left.\dagger\right)$.

\subsection{Fluorescence measurements}

Various nitrate solutions containing $\mathrm{Na}^{+}, \mathrm{K}^{+}, \mathrm{Mn}^{2+}, \mathrm{Ni}^{2+}, \mathrm{Zn}^{2+}$, $\mathrm{Pb}^{2+}, \mathrm{Cu}^{2+}, \mathrm{Cr}^{3+}, \mathrm{Fe}^{3+}, \mathrm{Hg}^{2+}, \mathrm{Cd}^{2+}, \mathrm{Co}^{2+}, \mathrm{Mg}^{2+}$, and $\mathrm{Al}^{3+}$ of $1 \mathrm{~mol} \mathrm{~L}^{-1}$ were used for testing the fluorescence performance of the gel BDG toward metal ions. All the fluorescence spectra experiments were implemented in a $\mathrm{DMF}-\mathrm{H}_{2} \mathrm{O}(1: 4, \mathrm{v} / \mathrm{v})$ binary system. Any fluorescence changes of the compounds were recorded upon the addition of nitrate salt, while the gelation concentration of the supramolecular gel was $0.5 \%$ in all the experiments. To further study the sensitivity of the gel BDG for $\mathrm{Al}^{3+}$ detection, the gelator $\mathrm{BD}$ in $\mathrm{DMF}$ and various concentrations of $\mathrm{Al}^{3+}$ aqueous solution were mixed intensively before measurement.

\section{Results and discussions}

\subsection{Formation of the gel BDG}

First of all, to exam the assembly ability and gelation properties of the gelator $\mathrm{BD}$, we configured $\mathrm{BD}$ in a variety of polar, nonpolar organic, and component solvents (organic solvents- $\mathrm{H}_{2} \mathrm{O}$ ), respectively, in the proportion of $5 \%$ and heated it completely. After cooling to room temperature, we found that BD could

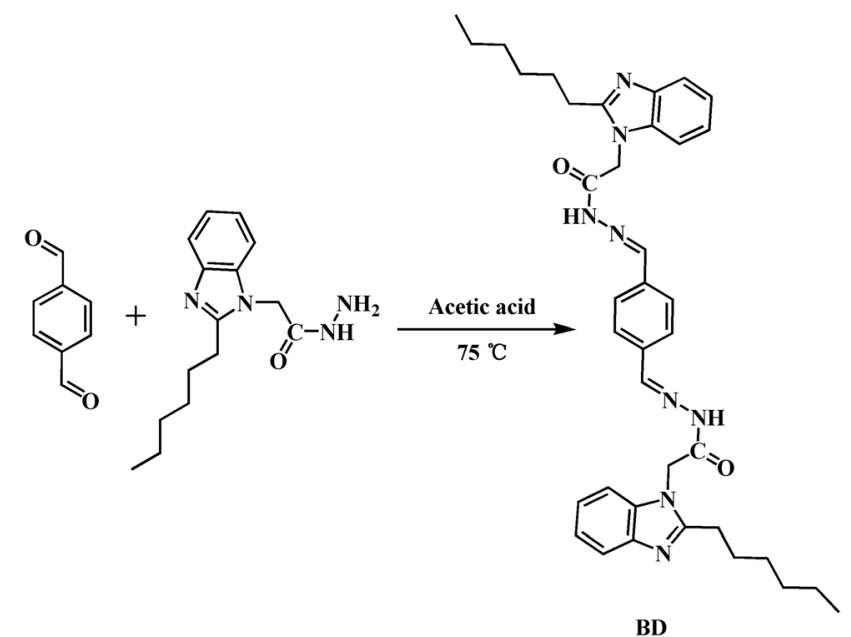

Scheme 2 Synthesis of the gelator BD
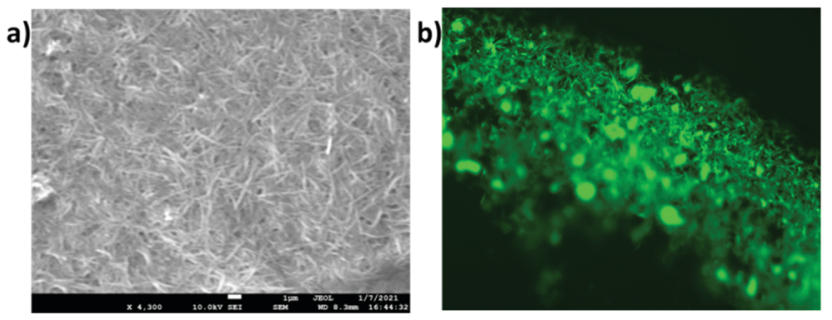

Fig. 1 (a) FE-SEM micrographs of the xerogel of BD. The gel was two days old before the images were taken. (b) FOM images of the BDG $(0.5 \%$, $\left.V_{\text {DMF }}: V_{\text {water }}=1: 4\right)$.

self-assemble into a stable gel only in DMF, DMF- $\mathrm{H}_{2} \mathrm{O}$ binary solution, DMSO, and DMSO- $\mathrm{H}_{2} \mathrm{O}$ binary solution. The successful preparation of the gel BDG was verified via a "stabilized reverse tube" method and the results are summarized in Table S1 (ESI $\dagger)$. As a general procedure, the compound BD (0.015 mmol) was completely dissolved in DMF $(0.4 \mathrm{~mL})$, then $\mathrm{H}_{2} \mathrm{O}(1.6 \mathrm{~mL})$ was added, dissolved completely by mixing as a hot solution, and finally the mixture was cooled to ambient temperature. As a vital parameter of supramolecular gel, we investigated the effect of different water contents on the assembly ability of the gel (Fig. S4, ESI $\dagger$ ), which was to play an important role when we were choosing the solvent composition of BD gel ( $V_{\mathrm{DMF}}: V_{\text {water }}=1: 4$, Fig. S5, ESI $\left.\dagger\right)$. In the DMF$\mathrm{H}_{2} \mathrm{O}$ binary system, with a water content less than $67.5 \%$, the gel of BD could not be obtained. Meanwhile, we also conducted partial tests for DMSO (Table S1, Fig. S6 and S7, ESI $\dagger$ ). By comparison, BD dissolved more quickly in DMF than in DMSO. The lowest critical gelation concentration (CGC) in DMF was $2.5 \%\left(\mathrm{w} / \mathrm{v} \%, 10 \mathrm{mg} \mathrm{mL}^{-1}=1.0 \%\right)$ and the gel-sol transition temperature $\left(T_{\text {gel }}\right)$ in DMF was $74{ }^{\circ} \mathrm{C}$. More interestingly, the CGC of the BD in DMF- $\mathrm{H}_{2} \mathrm{O}(1: 4, \mathrm{v} / \mathrm{v})$ was $0.5 \%$ and the $T_{\text {gel }}$ was $95{ }^{\circ} \mathrm{C}$ in $\mathrm{DMF}-\mathrm{H}_{2} \mathrm{O}(1: 4, \mathrm{v} / \mathrm{v})$. Hence, the $\mathrm{DMF}-\mathrm{H}_{2} \mathrm{O}(1: 4, \mathrm{v} / \mathrm{v})$ binary system was determined to be optimal for the formation of the gel BDG. As shown in Fig. 1a, the morphology structure of the BDG was further investigated by scanning electron microscopy (SEM), and was observed to be in a homogeneous uniform state. We could find that the large fibers exhibited some fine structure and appeared to be multi-layered. 3D entangled network structures comprising fibers with high aspect ratios were obtained, revealing well-ordered molecular packing properties. The fibers lacking twisting and regular shapes existed with widths of 200-500 nm and lengths of dozens of micrometers. As the FOM (fluorescent optical microscopy) images show, the morphology of BDG comprised dense aggregated bundles of fibers (Fig. 1b). Interestingly, a significantly yellow-green light could be achieved in the BDG.

\subsection{AIE behaviors}

As shown in Fig. 2, the solution of BD had inappreciable fluorescence. Also, while the emission intensity emerged rapidly, and reached a steady state finally at $\lambda=520 \mathrm{~nm}$, in the process, the temperature of the heated DMF/water solution declined under that of the $T_{\text {gel }}\left(T<T_{\text {gel }}\right)$ of BDG, which 


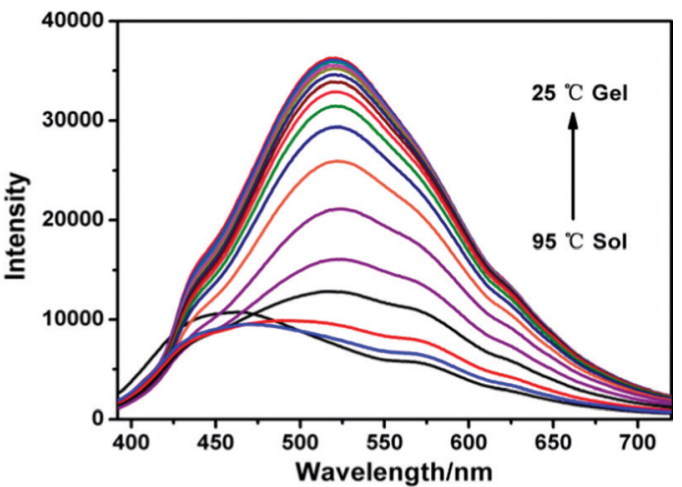

Fig. 2 Temperature-dependent fluorescent spectra of BDG ( $V_{D M F}$ : $\left.V_{\text {water }}=1: 4,0.5 \%\right)$ during the gelation process $\left(\lambda_{\mathrm{ex}}=372 \mathrm{~nm}\right)$.

indicated that the fluorescence of the supramolecular gel BDG was aggregation-induced emission (AIE), accompanied by yellow-green fluorescence. In order to indicate that this was not a purely thermal effect, we did another experiment as supplementary proof of the AIE properties of the BD gel (Fig. S8, ESI $\dagger$ ). From the experiment, we could see that BD powder $\left(25{ }^{\circ} \mathrm{C}\right)$ showed a yellow-green light under UV light, corresponding to the description in Fig. 2. However, this phenomenon did not exist in the BD powder $\left(25^{\circ} \mathrm{C}\right)$ under daylight or BD in DMF $\left(1 \times 10^{-4} \mathrm{M}, 25{ }^{\circ} \mathrm{C}\right)$ under UV light. This means that the molecule BD presented an interesting aggregation-induced emission phenomenon. BD was insoluble in water, and the fluorescence of $\mathrm{BD}$ in the aggregation state was also studied in $\mathrm{DMF} /$ water mixtures with different water fractions to investigate its solvent-dependent aggregation behavior (Fig. S9, ESI $\dagger$ ). The emission peak at $430 \mathrm{~nm}$ of $\mathrm{BD}\left(3 \times 10^{-4} \mathrm{M}\right)$ was very weak in DMF and almost kept constant until the water fraction reached $30 \%$. The fluorescence intensity of BD showed a remarkable enhancement caused by the intriguing AIE effect owing to the formation of aggregates when the water volume reached $40 \%$. Meanwhile, it exhibited an apparent red-shift (from $\lambda=430 \mathrm{~nm}$ to $520 \mathrm{~nm}$ ) with the increment of the water content. At about $70 \%$ water, the maximal emission intensity was achieved, which was almost 7 -fold greater than that in dilute solution. In the DMSO/water mixtures with different water fractions, BD showed a similar phenomenon (Fig. S10, ESI $\dagger$ ).

\subsection{Interaction of $\mathbf{A l}^{3+}$}

Investigations of BDG to assess the influence of metal ions on it in mixed solutions were performed (Fig. S11, ESI $\dagger$ ). The addition and diffusion of 10.0 equiv. of various metal ions $\left(\mathrm{Na}^{+}, \mathrm{K}^{+}\right.$, $\mathrm{Mn}^{2+}, \mathrm{Ni}^{2+}, \mathrm{Zn}^{2+}, \mathrm{Pb}^{2+}, \mathrm{Cu}^{2+}, \mathrm{Cr}^{3+}, \mathrm{Fe}^{3+}, \mathrm{Hg}^{2+}, \mathrm{Cd}^{2+}, \mathrm{Co}^{2+}, \mathrm{Mg}^{2+}$, and $\mathrm{Al}^{3+}$ using their nitrate salts as solutions) to $\mathrm{BD}$ generated the corresponding metallogels (such as BDG-Al). In the fluorescence spectrum, upon the addition of 10.0 equiv. $\mathrm{Al}^{3+}$ to the BDG in the process of gel formation, the emission of BDG showed an obvious blue-shift (Fig. 3), which indicated that $\mathrm{Al}^{3+}$ could be clearly detected using BDG. Considering the above interesting blue-shift in the fluorescence spectrum, the effects of various concentrations of $\mathrm{Al}^{3+}$ on the fluorescence spectrum

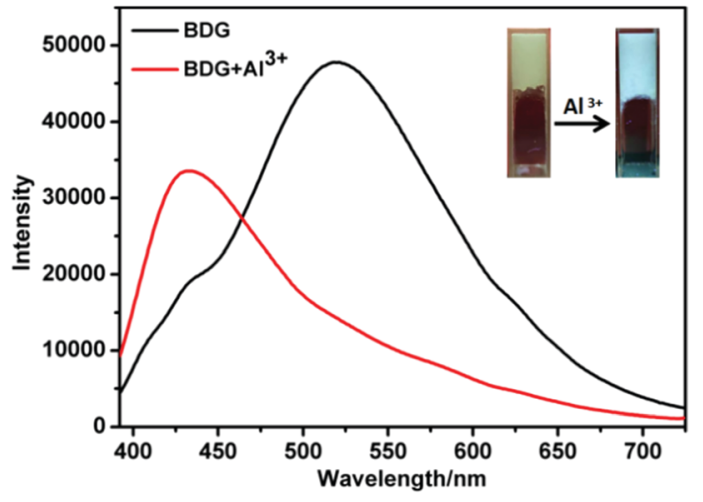

Fig. 3 Fluorescence spectra $\left(\lambda_{\text {ex }}=372 \mathrm{~nm}\right)$ of BDG $\left(0.5 \%, V_{\mathrm{DMF}}: V_{\text {water }}=\right.$ $1: 4)$ before and after the addition of $\mathrm{Al}^{3+}(10.0$ equiv.). Inset: Photographs showing the fluorescence change of BDG and BDG- $\mathrm{Al}^{3+}$ under illumination at $365 \mathrm{~nm}$.

of BDG were investigated in the gel state (Fig. S12, ESI $\dagger$ ). When the concentration of $\mathrm{Al}^{3+}$ was further increased, a blue-shift of $85 \mathrm{~nm}$ emerged; meanwhile, the original peak disappeared. Then the fluorescence intensity of BDG at $435 \mathrm{~nm}$ was enhanced gradually with the continuing increase in the $\mathrm{Al}^{3+}$ concentration. The fluorescent selectivity of BDG toward $\mathrm{Al}^{3+}$ may be attributed to the smaller ionic radius (0.5 ̊), which allowed a suitable coordination geometry with BD and a higher charge density that made $\mathrm{Al}^{3+}$ coordinate to $\mathrm{BD}$ strongly. ${ }^{25} \mathrm{In}$ the presence of the $\mathrm{Al}^{3+}$ ion, the carbonyl $\mathrm{O}$ and acylhydrazone $\mathrm{N}$ could coordinate with the $\mathrm{Al}^{3+}$ central atom, which increased the energies of the $n-p^{*}$ transitions compared to the corresponding $\mathrm{p}^{-} \mathrm{p}^{*}$ transitions, and finally the PET process was interrupted, and the fluorescence changed from yellow-green to blue emission. As the Job's plot experiments showed, we could see an obvious peak at $3: 7$ of $\mathrm{BDG}-\mathrm{Al}^{3+}$, assignable to the best composition ratio of $\mathrm{BDG}-\mathrm{Al}^{3+}(1: 2)$ (Fig. 4a). In terms of the performance of identifying $\mathrm{Al}^{3+}$, for example, Fig. $4 \mathrm{~b}$ shows an investigation in which various metal cations (including $\mathrm{Na}^{+}$, $\mathrm{K}^{+}, \mathrm{Mn}^{2+}, \mathrm{Ni}^{2+}, \mathrm{Zn}^{2+}, \mathrm{Pb}^{2+}, \mathrm{Cu}^{2+}, \mathrm{Cr}^{3+}, \mathrm{Fe}^{3+}, \mathrm{Hg}^{2+}, \mathrm{Cd}^{2+}, \mathrm{Co}^{2+}$, $\mathrm{Mg}^{2+}$, and $\mathrm{Al}^{3+}$ ) were put into dot arrays of $\mathrm{BD}$-gel, but only $\mathrm{Al}^{3+}$ gave BDG a bright sky-blue color under UV light at $365 \mathrm{~nm}$.

In addition, the response mechanism of the $\mathrm{BDG}$ for $\mathrm{Al}^{3+}$ was further investigated by ${ }^{1} \mathrm{H}$ NMR titration, IR, and XRD. In the ${ }^{1} \mathrm{H}$ NMR titrations of $\mathrm{Al}^{3+}$ for $\mathrm{BD}$ (Fig. 5) with the increasing concentration of $\mathrm{Al}^{3+}$, the $\mathrm{N}-\mathrm{H}\left(\mathrm{H}^{1}\right)$ signals showed a downfield shift. When adding proper $\mathrm{Al}^{3+}$, the weakness of the $\mathrm{N}-\mathrm{H}\left(\mathrm{H}^{1}\right)$ signal at $\delta 11.9 \mathrm{ppm}$ indicated that the deprotonation process had occurred. In the meanwhile, the hydrogen bond existing in the acylhydrazone group was destroyed during the coordination of $\mathrm{Al}^{3+}$ with the carbonyl group of $\mathrm{BD}$. Additionally, at low concentration of $\mathrm{BD},=\mathrm{CH}\left(\mathrm{H}^{2}\right)$ on $\mathrm{BD}$ appeared and its signals showed a downfield shift with the increasing concentration of $\mathrm{Al}^{3+}$. Therefore, a possible sensing mechanism based on deprotonation was proposed, as given in Fig. S13 (ESI $\dagger$ ). The XRD patterns of free BDG and BDG-Al (Fig. S14, ESI $\dagger$ ) showed $d$-spacings of $3.52 \AA$ and $11.45 \AA$ at $2 \theta=25.23^{\circ}$ and $7.71^{\circ}$, supporting the presence of $\pi-\pi$ stacking and hydrophobic 
a)
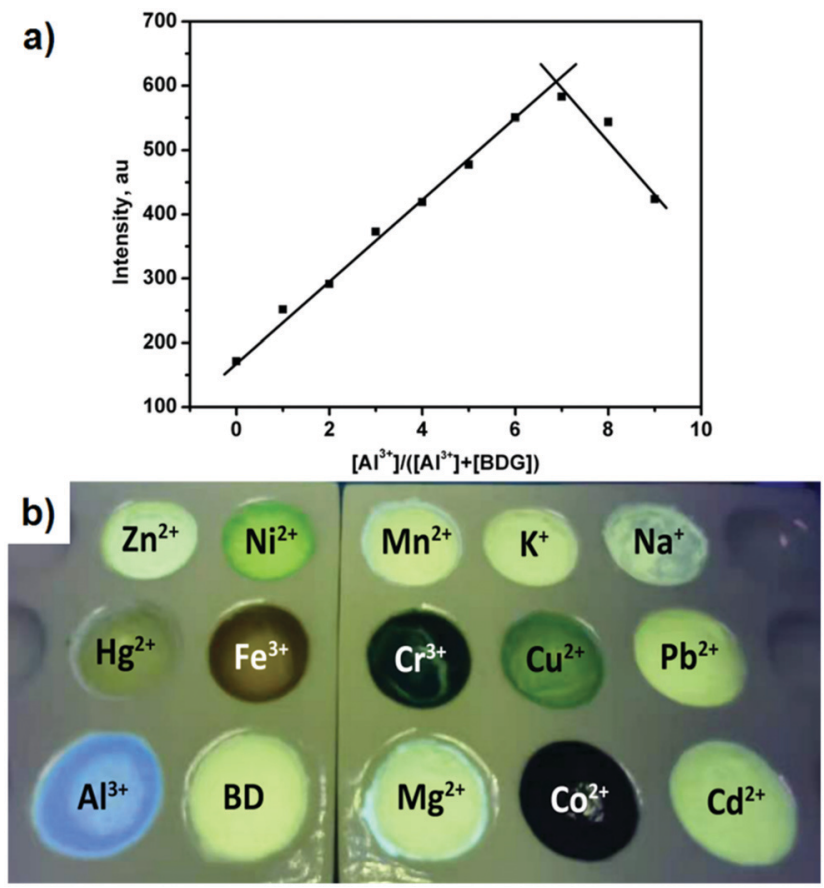

Fig. 4 (a) Job's plots according to the method for continuous variations, indicating the $1: 2$ stoichiometry for $\mathrm{BDG}-\mathrm{Al}^{3+}$ (the total concentration of $\mathrm{BD}$ and $\mathrm{Al}^{3+}$ was $1 \times 10^{-3} \mathrm{~mol} \mathrm{~L}^{-1}$ ). (b) Fluorescence responses of the $\mathrm{BD}$ gel-based sensor array to the presence of various cations under UV at $365 \mathrm{~nm}$. In gels, the concentration of BD in the sample was $0.5 \mathrm{wt} \%$.

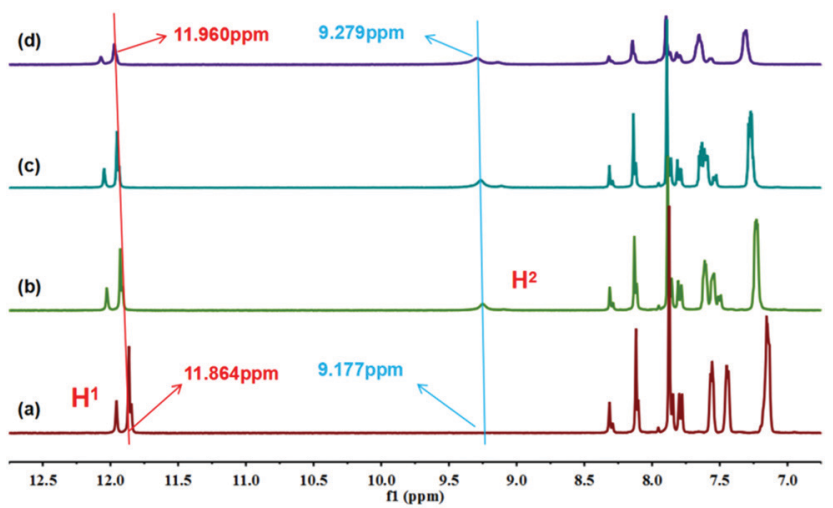

Fig. 5 Partial ${ }^{1} \mathrm{H}$ NMR spectra $(400 \mathrm{~Hz}, 298 \mathrm{~K})$ of $\mathrm{BD}\left(2.0 \times 10^{-2} \mathrm{M}\right)$ in DMSO- $d_{6}$ with increasing amounts of $\mathrm{Al}^{3+}\left(0.1 \mathrm{M}\right.$, DMSO- $\left.d_{6}\right)$, (a) free BD; (b) 1.0; (c) 2.0; (d) 5.0 equiv.

interaction in the BD. In the meantime, $d$-spacings of $3.51 \AA$ and $3.80 \AA$ at $2 \theta=25.37^{\circ}$ and $23.34^{\circ}$ suggested that the $\pi-\pi$ stacking remained in the metallogel BDG-Al. FT-IR spectra of the powder gelator $\mathrm{BD}$ and the xerogel BDG-Al were obtained to deeply understand the coordination of $\mathrm{Al}^{3+}$ and the gelator $\mathrm{BD}$ (Fig. S15, ESI $\dagger$ ). The bands at 1695 and $1596 \mathrm{~cm}^{-1}$ corresponding to $V(\mathrm{C}=\mathrm{O})$ and $V(\mathrm{C}=\mathrm{N})$ were revealed to be present in the IR spectrum of the gelator BD. However, with the addition of 2.0 equiv. of $\mathrm{Al}^{3+}$ and the formation of the $\mathrm{Al}^{3+}$ coordinated metallogel BDG-Al, the $V(\mathrm{C}=\mathrm{N})$ band was shifted to a lower wavenumber $\left(1562 \mathrm{~cm}^{-1}\right)$, respectively, due to coordination with the metal center.

\subsection{Light-harvesting ability}

Due to the unique AIE effect, compound BD in the aggregated form exhibited a broad emission at $520 \mathrm{~nm}$, which enables BD to act as a remarkable donor in gels. The potential fluorescence resonance energy transfer (FRET) between AIE (BDG) and various acceptors was next investigated. Sulforhodamine 101 (SR 101), acridine red, rhodamine 6G (Rh 6G), and rhodamine B ( $\mathrm{Rh} B$ ) were selected as energy acceptors, respectively, since they show strong absorption in the visible region and overlap with the emission from BDG. As shown in Fig. 6a, and Fig S16a, S16c, and S16e (ESI + ), the absorption band of these dye molecules overlapped well with the fluorescence emission of the BD assembly. On the other hand, a key parameter in facilitating an efficient energy-transfer process is spatially well-organized chromophores. This could be realized in between the BD assembly and the dyes. As shown in Fig. 6b, with the gradual addition of dye SR 101, the fluorescence intensity of BDG decreased significantly, while the fluorescence emission band of SR 101 appeared and increased when excited at $372 \mathrm{~nm}$, accompanied with a change in the emission color from green/yellow to red under a UV lamp.

The fluorescence quantum yield of the BDG/SR 101 system was estimated to be $13.28 \%$ (Fig. S17a, ESI $\dagger$ ). According to

a)
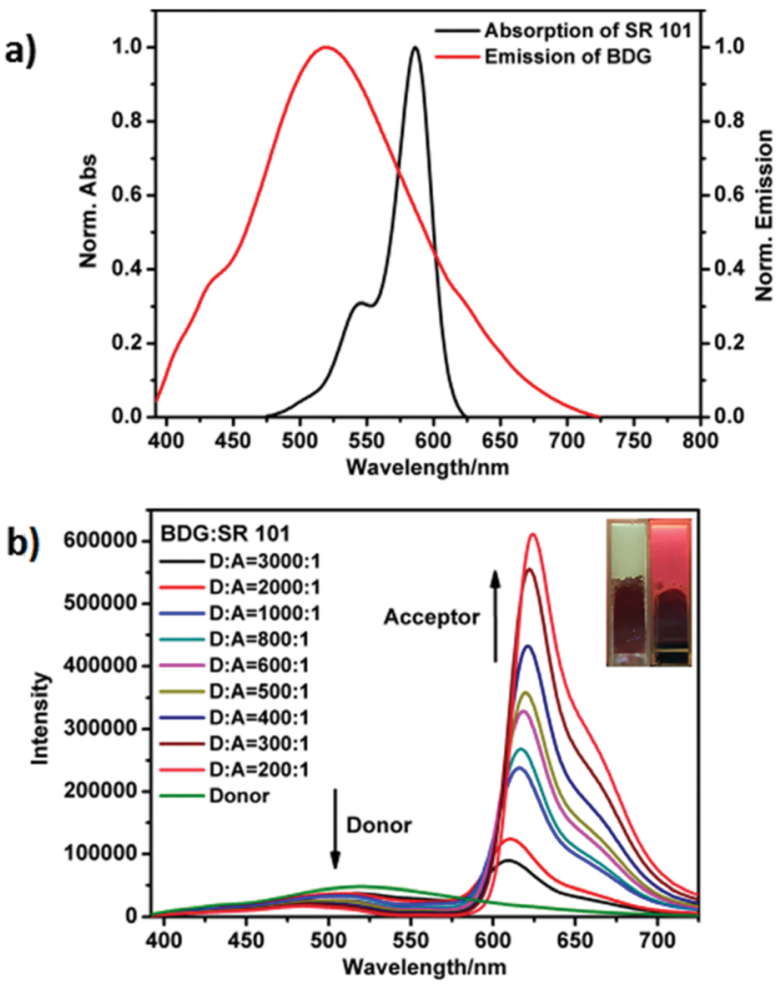

Fig. 6 (a) Normalized emission spectrum of BDG (7.7 mM), absorption spectrum of SR $101\left(1 \times 10^{-5} \mathrm{M}\right)$. (b) Fluorescence spectra of BDG $(7.7 \mathrm{mM})$ in the gel with different concentrations of SR $101\left(38.5 \mu \mathrm{M}, \lambda_{\mathrm{ex}}=372 \mathrm{~nm}\right.$, Inset: photographs of BDG, BDG/SR 101 under UV light). 
fluorescence titration spectrum, the energy-transfer efficiency was calculated to be $80 \%$ (Fig. S18a, ESI $\dagger$ ) at a donor/acceptor ratio of $200: 1$. Upon the gradual addition of acridine red, $\mathrm{Rh}$ $6 \mathrm{G}$, and $\mathrm{Rh} \mathrm{B}$ as acceptors to the $\mathrm{BD}$ assembly, respectively, the emission peak of BDG began to decay while the emissive intensity of the acceptors kept increasing (Fig S16b, S16d, and S16f, ESI $\dagger$ ). According to fluorescence titration spectrum, the energy-transfer efficiencies ( $\Phi_{\mathrm{ET}}$ ) of acridine red, Rh 6G, and $\mathrm{Rh} \mathrm{B}$ as acceptors were calculated to be $98 \%$, 99\%, and $98 \%$ (Fig S18b, S18c, and S18d, ESI $\dagger$ ). The fluorescence quantum yields of the acridine red, $\mathrm{Rh} 6 \mathrm{G}$, and $\mathrm{Rh} \mathrm{B}$ systems were estimated to be $14.99 \%, 11.88 \%$, and $7.51 \%$ (Fig. S17b, S17c, and $\mathrm{S} 17 \mathrm{~d}, \mathrm{ESI} \dagger)$.

Furthermore, to clearly show the energy transfer (ET) from BDG to the acceptors during the gelation process, we measured the fluorescence spectra of gelation in energy-transfer systems (Fig. S19, ESI $\dagger$ ). In view of the rapid gelation of $\mathrm{BD}$, we performed the experiment at lower concentrations. Primarily, when adding SR 101 into BDG (molar ratio of BDG: SR 101 was $3000: 1)$ in $\mathrm{DMF} / \mathrm{H}_{2} \mathrm{O}$ solution, the fluorescence spectrum of BDG/SR 101 showed a continuous significant increase at $610 \mathrm{~nm}$ during the gelation process (Fig. S19a, ESI $\dagger$ ). In addition, compared with the emission spectrum of BDG (Fig. S20, $\mathrm{ESI} \dagger$ ) at the same concentration, the fluorescence intensity of BDG/SR 101 at $515 \mathrm{~nm}$ after 10 min was only half as much as the intensity of BDG. Finally, the morphologies of BDG/SR 101, BDG/acridine red, BDG/Rh $6 \mathrm{G}$ and BDG/Rh B were investigated by scanning electron microscopy (SEM) (Fig. S21, ESI $\dagger$ ). The SEM images of the light-harvesting systems showed a number of micron rod-like structures. The transformation from network structures into stick structures indicated that the dye molecules could create an interaction with BDG to change the previous intramolecular interactions; thereby the formation of a rod-like supramolecular structure was observed. Subsequently, the fluorescent optical microscopy (FOM) images further truly reflected the morphology and luminescence phenomenon of the light-harvesting systems (Fig. S22, ESI $\dagger$ ).

\section{Conclusion}

In conclusion, we designed a novel organogelator $\mathrm{BD}$ that could be self-assembled into an organogel BDG showing strong AIE. The supramolecular gel BDG can serve both as a selective fluorescence sensing system for $\mathrm{Al}^{3+}$ and light-harvesting energy donor with several kinds of dyes through the FRET mechanism. Notably, the supramolecular coordination complexes $\mathrm{BDG}^{-\mathrm{Al}^{3+}}$ formed by the metal-coordination-driven self-assembly emitted from yellow-green to sky-blue as the concentration of $\mathrm{Al}^{3+}$ increased. The fluorescence emission from yellow-green to red was also obtained via the host-guest interactions in artificial light-harvesting systems. This simple bi-acylhydrazone demonstrates an example of a multifunctional light-emitting material including AIE activity, lightharvesting abilities, sensing properties, and so on.

\section{Conflicts of interest}

There are no conflicts to declare.

\section{Acknowledgements}

This work was supported by the National Natural Science Foundation of China (No. 21961029), Key Research Foundation of Department of Science and Technology of Ningxia, China (No. 2019BDE03019, 2018BEG03020), The Natural Science Foundation of Ningxia, China (No. 2020AAC02031); CAS "Light of West China" (No. 2017-32), The Science and Technology Foundation of Guyuan, China (No. 2019GKGY025), Research Award Fund for First-class Discipline Construction (Education Discipline) in Higher Education Institutions of Ningxia, China (No. NXYLXK2017B11), The Foundation of Ningxia Normal University (No. NXSFZDA1905), Engineering Research Center of Liupanshan, School Chemistry and Chemical Engineering of Ningxia Normal University (No. HGZD21-02), are gratefully acknowledged.

\section{Notes and references}

1 J. Luo, Z. Xie, J. W. Y. Lam, L. Cheng, H. Chen, C. Qiu, H. S. Kwok, X. Zhan, Y. Liu, D. Zhu and B. Z. Tang, Aggregation-induced emission of 1-methyl-1,2,3,4,5pentaphenylsilole, Chem. Commun., 2001, 1740-1741.

2 H. Zhou, M. H. Chua, B. Z. Tang and J. Xu, Aggregationinduced emission (AIE)-active polymers for explosive detection, Polym. Chem., 2019, 10, 3822-3840.

3 (a) L. Chen, D. Wu, C. S. Lim, D. Kim, S. J. Nam, W. Lee, G. Kim, H. M. Kim and J. Yoon, A two-photon fluorescent probe for specific detection of hydrogen sulfide based on a familiar ESIPT fluorophore bearing AIE characteristics, Chem. Commun., 2017, 53, 4791-4794; (b) J. Yang, X. L. Liu, H. L. Wang, H. Q. Tan, X. X. Xie, X. Zhang, C. C. Liu, X. Qu and J. L. Hua, A turn-on near-infrared fluorescence probe with aggregation-induced emission based on dibenzo[a,c]phenazine for detection of superoxide anions and its application in cell imaging, Analyst, 2018, 143, 1242-1249; (c) D. Dai, Z. Li, J. Yang, C. Wang, J. R. Wu, Y. Wang, D. Zhang and Y. W. Yang, Supramolecular Assembly-Induced Emission Enhancement for Efficient Mercury(II) Detection and Removal, J. Am. Chem. Soc., 2019, 141, 4756-4763.

4 (a) Y. Zhang, Y. Chen, X. Li, J. Zhang, J. Chen, B. Xu, X. Fu and W. Tian, Folic acid-functionalized AIE Pdots based on amphiphilic PCL- $b$-PEG for targeted cell imaging, Polym. Chem., 2014, 5, 3824-3830; (b) X. Zhang, K. Wang, M. Liu, X. Zhang, L. Tao, Y. Chen and Y. Wei, Polymeric AIE-based nanoprobes for biomedical applications: recent advances and perspectives, Nanoscale, 2015, 7, 11486-11508; (c) S. Chen, H. Wang, Y. Hong and B. Z. Tang, Fabrication of fluorescent nanoparticles based on AIE luminogens (AIE dots) and their applications in bioimaging, Mater. Horiz., 2016, 3, 283-293; (d) Y. Hu, X. Liang, Z. Zhuang, Z. Cao, 
Q. Qi, Y. Wang, Y. Mi, Z. Zhao and Q. Cui, Cell-penetrating peptide modified AIE polymeric nanoparticles by miniemulsion polymerization and application for cell fluorescence imaging, Polym. Chem., 2019, 10, 4220-4228.

5 H. T. Feng, Y. X. Yuan, J. B. Xiong, Y. S. Zheng and B. Z. Tang, Macrocycles and cages based on tetraphenylethylene with aggregation-induced emission effect, Chem. Soc. Rev., 2018, 47, 7452-7476.

6 J. G. Wang, X. G. Gu, P. F. Zhang, X. B. Huang, X. Y. Zheng, M. Chen, H. T. Feng, R. T. K. Kwok, J. W. Y. Lam and B. Z. Tang, Ionization and Anion- $\pi^{+}$Interaction: A New Strategy for Structural Design of Aggregation-Induced Emission Luminogens, J. Am. Chem. Soc., 2017, 139, 16974-16979.

7 J. Mei, N. L. Leung, R. T. Kwok, J. W. Lam and B. Z. Tang, Aggregation-Induced Emission: Together We Shine, United We Soar!, Chem. Rev., 2015, 115, 11718-11940.

8 (a) X. Ji, K. Jie, S. C. Zimmerman and F. H. Huang, A double supramolecular crosslinked polymer gel exhibiting macroscale expansion and contraction behavior and multistimuli responsiveness, Polym. Chem., 2015, 6, 1912-1917; (b) X. Ji, B. Shi, H. Wang, D. Xia, K. Jie, Z. L. Wu and F. H. Huang, Supramolecular Construction of Multifluorescent Gels: Interfacial Assembly of Discrete Fluorescent Gels through Multiple Hydrogen Bonding, Adv. Mater., 2015, 27, 8062-8066; (c) M. H. Liu, G. H. Ouyang, D. Niu and Y. T. Sang, Supramolecular gelatons: towards the design of molecular gels, Org. Chem. Front., 2018, 5, 2885-2900.

9 J. J. Park, Y. H. Kim, C. Kim and J. M. Kang, Naked eye detection of fluoride and pyrophosphate with an anion receptor utilizing anthracene and nitrophenyl group as signaling group, Tetrahedron Lett., 2011, 52, 2759-2763.

10 (a) Y. J. Kim, H. Kwak, S. J. Lee, J. S. Lee, H. J. Kwon, S. H. Nam, K. Lee and C. Kim, Urea/thiourea-based colorimetric chemosensors for the biologically important ions: efficient and simple sensors, Tetrahedron, 2006, 62, 9635-9640; (b) X. X. Ma, Z. F. Zhang, H. P. Xie, Y. H. Ma, C. H. Liu, S. W. Liu and M. H. Liu, Emissive intelligent supramolecular gel for highly selective sensing of $\mathrm{Al}^{3+}$ and writable soft material, Chem. Commun., 2018, 54, 13674-13677.

11 S. Samanta, S. Goswami, M. N. Hoque, A. Ramesh and G. Das, An aggregation-induced emission (AIE) active probe renders $\mathrm{Al}(\mathrm{III})$ sensing and tracking of subsequent interaction with DNA, Chem. Commun., 2014, 50, 11833-11836.

12 S. Goswami, K. Aich, S. Das, A. K. Das, D. Sarkar, S. Panja, T. K. Mondal and S. Mukhopadhyay, A red fluorescence 'offon' molecular switch for selective detection of $\mathrm{Al}^{3+}, \mathrm{Fe}^{3+}$ and $\mathrm{Cr}^{3+}$ : experimental and theoretical studies along with living cell imaging, Chem. Commun., 2013, 49, 10739-10741.

13 G. Crisponi, D. Fanni, C. Gerosa, S. Nemolato, V. M. Nurchi, M. Crespo-Alonso, J. I. Lachowicz and G. Faa, The meaning of aluminium exposure on human health and aluminiumrelated diseases, Biomol. Concepts, 2013, 4, 77-87.

14 (a) S. Jiao, X. C. Wang, Y. H. Sun, L. J. Zhang, W. H. Sun, Y. Sun, X. H. Wang, P. Y. Ma and D. Q. Song, A novel fluorescein-coumarin-based fluorescent probe for fluoride ions and its applications in imaging of living cells and zebrafish in vivo, Sens. Actuators, B, 2018, 262, 188-194; (b) W. Y. Feng and G. Q. Feng, A readily available colorimetric and near-infrared fluorescent turn-on probe for detection of carbon monoxide in living cells and animals, Sens. Actuators, B, 2018, 255, 2314-2320.

15 Y. Zhu, L. Xu and L. Wang, Effect of scaffold structures on the artificial light-harvesting systems: a case study with an AIEE-active pillar[5]arene dyad, Chem. Commun., 2019, 55, 5910-5913.

16 T. Xiao, W. Zhong and L. Zhou, Artificial light-harvesting systems fabricated by supramolecular host-guest interactions, Chin. Chem. Lett., 2019, 30, 31-36.

17 J. L. Herek, W. Wohlleben and R. J. Cogdell, Quantum control of energy flow in light harvesting, Nature, 2002, 417, 533-535.

18 S. Kundu and A. Patra, Nanoscale Strategies for Light Harvesting, Chem. Rev., 2016, 117, 712-757.

19 (a) C. Curutchet and B. Mennucci, Quantum Chemical Studies of Light Harvesting, Chem. Rev., 2017, 117, 294-343; (b) M. J. Sun, Y. Y. Liu, W. Zeng, Y. S. Zhao, Y. W. Zhong and J. N. Yao, Photoluminescent Anisotropy Amplification in Polymorphic Organic Nanocrystals by Light-Harvesting Energy Transfer, J. Am. Chem. Soc., 2019, 141, 6157-6161.

20 (a) H. Q. Peng, L. Y. Niu, Y. Z. Chen, L. Z. Wu, C. H. Tung and Q. Z. Yang, Biological Applications of Supramolecular Assemblies Designed for Excitation Energy Transfer, Chem. Rev., 2015, 115, 7502-7542; (b) Z. X. Liu, X. H. Sun, X. Y. Dai, J. J. Li, P. Y. Lia and Y. Liu, Sulfonatocalix[4]arene-based light-harvesting amphiphilic supramolecular assemblies for sensing sulfites in cells, J. Mater. Chem. C, 2021, 9, 1958-1965.

21 X. M. Li, S. P. Qiao, L. L. Zhao, S. D. Liu, F. Li, F. H. Yang, Q. Luo, C. X. Hou, J. Y. Xu and J. Q. Liu, Template-Free Construction of Highly Ordered Monolayered Fluorescent Protein Nanosheets: A Bioinspired Artificial LightHarvesting System, ACS Nano, 2019, 13, 1861-1869.

22 M. R. Wasielewski, Self-Assembly Strategies for Integrating Light Harvesting and Charge Separation in Artificial Photosynthetic Systems, Acc. Chem. Res., 2009, 42, 1910-1921.

23 (a) A. Ajayaghosh, V. K. Praveen and C. Vijayakumar, Organogels as scaffolds for excitation energy transfer and light harvesting, Chem. Soc. Rev., 2008, 37, 109-122; (b) L. K. Ji, Y. T. Sang, G. H. Ouyang, D. Yang, P. F. Duan, Y. Q. Jiang and M. H. Liu, Cooperative Chirality and Sequential Energy Transfer in a Supramolecular Light-Harvesting Nanotube, Angew. Chem., Int. Ed., 2019, 58, 844-848.

24 (a) M. L. Saha, X. Z. Yan and P. J. Stang, Photophysical properties of organoplatinum(II) compounds and derived self-assembled metallacycles and metallacages: Fluorescence and its applications, Acc. Chem. Res., 2016, 49, 2527-2539; (b) M. M. Zhang, S. C. Yina, J. Zhang, Z. X. Zhou, M. L. Saha, C. J. Lu and P. J. Stang, Metallacycle-cored supramolecular assemblies with tunable fluorescence including white-light emission, Proc. Natl. Acad. Sci. U. S. A., 2017, 114, 3044-3049. 
25 (a) A. Sahana, A. Banerjee, S. Das, S. Lohar, D. Karak, B. Sarkar, S. K. Mukhopadhyay, A. K. Mukherjee and D. Das, A naphthalene-based $\mathrm{Al}^{3+}$ selective fluorescent sensor for living cell imaging, Org. Biomol. Chem., 2011, 9,
5523-5529; (b) K. Tiwari, M. Mishra and V. P. Singh, A highly sensitive and selective fluorescent sensor for $\mathrm{Al}^{3+}$ ions based on thiophene-2-carboxylic acid hydrazide Schiff base, RSC Adv., 2013, 3, 12124-12132. 